\title{
Celebrating the International Year of Plant Health 2020 (IYPH 2020)
}

The COVID-19 pandemic clearly illustrates the impact of a microbial disease outbreak on the human population. Throughout the course of human history, microbial plant diseases and insect pests have had a similar impact, resulting in loss of life due to food shortages. Notable examples include the Irish potato famine in the 1840s caused by Phytophthora infestans and the more recent locust swarms in East Africa. Conservative estimates predict that up to 5 million people may be at risk of starvation due to this locust invasion. Yet, despite years of extensive research, we still lack a comprehensive understanding of, for example, host-pathogen interactions and resistance mechanisms deployed by plants.

In this special issue, we highlight research on plant health by pathologists and entomologists in South Africa. The Commentary by Mirko Montuori from the Food and Agricultural Organization (FAO) provides a clear synthesis of contemporary plant health research. He discusses the concept of how protecting plants directly protects human health. This topic is explored further by Ida Wilson who specifically discusses the importance of plant health for sustainable crop production in South Africa. Her suggestion is that a holist approach should be implemented when considering a management strategy against pests and pathogens.

Microbe and insect collections may be considered national biodiversity resources. These collections, which detail the historical records of disease and pest outbreaks, are important for decision-makers as they contain critical information for phytosanitary regulations. In her insightful Commentary, Adriaana Jacobs outlines the importance of these natural science collections, one of which has a long and sustained history in South Africa; for instance, the national fungal culture collection was established in 1905.

The Southern African Society of Plant Pathology and Microbiology was formed in 1962. Initially the presentations at the annual congresses focused on plant pathogens, but this changed in the 1970s with microbiological topics dominating proceedings. In 1980, the disciplines split into the South African Society of Microbiology and the Southern African Society of Plant Pathology. In our Commentary, Mike Wingfield and I describe the history of the Southern African Society of Plant Pathology, which has developed into a highly successful professional society.

One of the primary objectives of plant pathologists is to manage diseases to prevent significant economic losses. In 1926, Paul van der Bijl, the head of the Department of Plant Pathology and Mycology at Stellenbosch University, wrote a seminal paper in the South African Journal of Science on 'Landmarks in the development of the science of plant pathology and of disease control'. In his Commentary on this article, Bernard Slippers compares key factors that influence plant disease development and management today compared with what was known almost 100 years ago. One of the most renowned epidemiologists in the world during the 20th century was James E. Vanderplank, and Mike Wingfield, Andre Drenth and I present the achievements of this most remarkable scientist in our Commentary. In the contribution by Trudy Paap and colleagues, the epidemiology in South Africa of an invasive exotic pest, the shot hole borer, is discussed. Although initially only a problem in the urban environment, it is now a tremendous threat to agriculture and forestry.
Victoria Pastor from Jaume I University in Spain reviewed two volumes of the book Plant Health Under Biotic Stress', edited by Dr Rizwan Ali Ansari and Dr Irshad Mahmood. Volume 1 focuses on organic strategies while Volume 2 examines microbial interactions. She entitled her review 'Green actions for a better plant health', thus highlighting the trend towards using biological alternatives as opposed to pesticides to manage plant pests and diseases.

This year (2020) the National Science and Technology Forum (NSTF) included a special category to celebrate the IYPH 2020. Several distinguished plant pathologists and entomologists were nominated for this award and Mike Wingfield, a highly accomplished researcher in the field of forest protection, received the award. Salmina Mokgehle, a South African Journal of Science Associate Editor mentee, who has been integrally involved in the compilation of this special issue, interviewed Mike. Her Profile of Mike's accomplishments over the course of his 40year career is included in this issue.

This issue also includes six review articles focusing on viruses and other pathogens that have caused, and remain the cause of, significant losses to the agricultural and forestry sectors in South Africa. The first, written by Chrissie Rey, is similar to a detective story as it records the early history of the discovery of plant viruses in the country. The two reviews by Jacquie van der Waals and Kerstin Krüger cover the diseases and the vectors of the most important pathogens affecting potato production areas in South Africa. Mike Wingfield and co-authors reflect on the history of forest protection in South Africa while Zakkie Pretorius discusses the accomplishments of his group in wheat rust research over the past 40 years. Kwasi Yobo and co-authors highlight the importance of Fusarium head blight on wheat and emphasise the significance of multiple strategies to manage the disease.

The six research articles focus almost entirely on plant diseases. Although attempts were made to encourage submissions from applied entomologists, none was received. Some of the most devastating plant diseases in South Africa are thus the core of these articles. Our collection includes research undertaken by Maryke Craven and co-authors on northern corn leaf blight as a predisposing factor of ear rot incidence and severity; the development and improvement of an epidemiological model for citrus black spot by Providence Moyo and colleagues; and the first report of tropical race 4 (TR4) of the pathogen responsible for Fusarium wilt of banana in Mozambique by Altus Viljoen and his collaborators. The occurrence of TR4 in Mozambique is considered a major threat to banana production in the rest of Africa. Mapotso Kena and her colleagues describe the use of plant extracts (from Monsonia burkeana and Moringa oleifera) and Trichoderma harzianum as a biocontrol option to manage damping-off of tomato seedlings caused by Rhizoctonia solani. Research by Kwasi Yobo and co-authors on the entomopathogenic fungus and endophyte, Beauvaria bassiana, as a control measure against the rice stem borer is also included. Finally, Dave Berger and his team determined that northern corn leaf blight is the most serious disease of maize in smallholder farms in South Africa and that it can be successfully managed by the deployment of resistant cultivars.

We hope that you enjoy reading this special issue in honour of the IYPH 2020 